\title{
Combined Chelation Therapy with Deferasirox and Desferrioxamine In Removing Lead from Rats
}

\author{
Faezeh Dahooee Balooch, Seyed Jamilaldin Fatemi, \\ Marzieh Iranmanesh and Batool Hosseinkhani
}

Department of Chemistry, Faculty of Sciences, Shahid Bahonar University of Kerman, Kerman 76169, Iran

\begin{abstract}
The present study aimed to evaluate the potential efficiency of Deferasirox (DFX) and Desfferioxamine (DFO) as chelating agents in removing lead from rats as a biological model. Two different doses of lead (II) chloride ( 40 and $80 \mathrm{mg} \mathrm{kg}^{-1}$ body weight) were used for 45 days. After this period, all rats showed toxicity symptoms through loss of hair, greenish mottling on the liver, appearance of red dots around eyes and weakness. After lead administration, chelation therapy was done in removing the toxic metal from the biological system. The abilities of DFX and DFO chelators in removal of lead from the body were studied for 10 days. Lead and iron concentrations in different tissues were measured by Flame Atomic Absorption Spectroscopy (FAAS). Our results showed that two chelators can be more effective as combined therapy than as single therapy in removing lead from the body and also, toxicity symptoms are decreased. It could be concluded that DFX and DFO chelators could be used for the treatment of complication of lead intoxication symptoms.
\end{abstract}

Keywords: Deferasirox, Lead Toxicity, Rats, Desferrioxamine, Chelation Therapy

\section{INTRODUCTION}

Lead intoxication is one of the leading occupational health problems. This metal causes a broad range of biochemical, physiological and behavioral dysfunctions. Lead is recognized as a dangerous neurotoxin, even at low levels of exposure (Sansar et al., 2011). Many heavy metals, including lead, are known to induce over production of Reactive Oxygen Species (ROS) and consequently enhance lipid peroxidation, decrease the saturated fatty acids and increase the unsaturated fatty acid contents of membranes (Ibrahim et al., 2012). ROS are the byproducts of many degenerative reactions in many tissues, which will affect the regular metabolism by damaging the cellular components (Foyer and Noctor, 2002). Many authors propose that the formation of free radicals is the most important molecular mechanism of the lead toxicity (Navarro-Moreno et al., 2009). Only one hour after intestinal absorption, lead accumulates in bone, kidney, liver and other organs (Navarro-Moreno et al.,
2009). Several studies have shown that lead can accumulate in the brain when its concentration in the blood is elevated. Lead causes damage to various systems of the body including the Central Nervous System (CNS) (Sansar et al., 2011). Lead is translocate through the food chain to man and animals, its toxicity depends on its chemical form administrated to the animal, the route of administration and the frequency and duration administered to animals. Lead can affect individuals of any age, but it has a disproportionate effect on children because their behavioral patterns place them at higher risk for exposure to lead. Their bodies absorb a larger percentage of the lead that they ingest and they exhibit lead toxicity at lower level for exposure than adults do. Accumulation of lead produces damaging effects in the hematopoetical, hematic, renal and gastrointestinal system (Ibrahim et al., 2012). The toxicity of lead is closely related to age, sex, route of exposure level of intake, solubility, metal oxidation state, retention percentage and duration of exposure, frequency

Corresponding Author: Faezeh Dahooee Balooch, Department of Chemistry, Faculty of Sciences, Shahid Bahonar University of Kerman, Kerman 76169, Iran 
of intake, absorption rate, mechanisms and efficiency of excretion. Lead has been associated with various forms of cancer, nephrotoxicity, central nervous system effects and cardiovascular diseases in human (Ibrahim et al., 2012). A medical treatment to remove toxic elements from the body is chelation therapy. It involves the use of ligating drugs that binds metals for the treatment of intoxication. These chelating agents promote the excretion and subsequent depletion of the transition metal in biological systems (Tubafard et al., 2010). These chelating agents consist of a range of bidentate, tridentate and hexadentate ligands in which two, three or six atoms are able to coordinate, respectively (Fatemi et al., 2011). Clinical evaluations of some chelators for removal of toxic metal in rats have been previously reported (Amiri et al., 2007; Fatemi et al., 2009; 2011; Saljooghi and Fatemi, 2010; 2011). In this way, chelator is added to the blood through a vein or administered orally in order to eliminate toxic elements. Deferasirox (4-[3, 5-bis (2-hydroxyphenyl)-1,2,4-triazol-1-yl]benzoic acid, ICL670, DFX, Fig. 1a) was first reported in 1999 (Heinz et al., 1999). DFX is an oral iron chelating agent taken once daily. It is a tridentate chelator with high selectivity for $\mathrm{Fe}^{3+}$. It selectivity binds $\mathrm{Fe}^{3+}$ over $\mathrm{Fe}^{2+}$ and shows little affinity for other divalent ions such as $\mathrm{Zn}^{2+}$ or $\mathrm{Cu}^{2+}$ (Saljooghi and Fatemi, 2011). In vivo, this selectivity is demonstrated by conserved plasma $\mathrm{Zn}$ and $\mathrm{Cu}$ levels in patients taking DFX and while its efficacy is rather low for inducing negative iron balance, it is effective and well tolerated (Saljooghi and Fatemi, 2010). DFX possesses relatively high lipophilicity with a $\log \mathrm{P}_{\text {Octano/ water value of } 3.8 \text {, which }}$ permits effective absorption from the gastrointestinal tract (Ma et al., 2012). DFX, because of its proven efficacy and oral administration, has been recognized as the first-choice agent for ICT in transfusion-dependent subjects (List et al., 2009). Desferrioxamine (DFO, Fig. 1B) was introduced in the 1960's and Iron Chelation Therapy (ICT) with DFO, is current standard for the treatment of iron overload in patients with transfusion dependent disorders such as $\beta$-thalassemia. Although DFO is large and high hydrophilic molecule (log D7.4 $=-2 ; \mathrm{n}$-octanol/Tris $\mathrm{HCl}$ [20mM, pH 7.4]), it gains entry into the liver via a facilitated transport system. It can, therefore, interact with both hepatocellular and extracellular iron promoting urinary and biliary iron excretion (Ma et al., 2012). Its oral use is restricted because of high molecular weight and therefore subcutaneous or intravenous administration is usual. Two chelators (DFX and DFO) have different abilities through the organism. Hence, it is better these chelators be used as a combination. This combined therapy is based on the hypothesis that various chelating agent can mobilize toxic element from different tissues and therefore better result could be expected. Recent studies with chelators that have different lipophilic properties as combined therapy have shown favorable efficacy to mobilize mercury and cadmium (Tubafard et al., 2010). Results of this kind of combined chelation therapy has been proved by Fatemi et al. (2009); Amiri et al. (2007); Tubafard and Fatemi (2008); Tubafard et al. (2010); Fatemi et al., (2011; 2012) and Iranmanesh et al. (2013). The aim of this study was to investigate the chelating potency of DFX and DFO. Testing was done by using an acute experimental model on rats with single or combined chelators given shortly after lead administration. This research indicates that this procedure might be effective for preliminary testing of the efficacy of the chelating agents in lead removing from human body.

\section{MATERIALS AND METHODS}

\subsection{Materials}

Lead (II) chloride, DFO and other materials were purchased from Merck Chemicals Co. and DFX was purchased from Novartis Co. (Basel, Switzerland).

\subsection{Animals and Experimental Procedure}

Male Wistar rats were obtained from Kerman Neuroscience Research Center (Kerman, Iran). They kept in animal house at this center. The animals were kept under a controlled light: dark (12:12 h) schedule at 231 and humidity $50 \%$. The rats were divided randomly to control and treated groups and were maintained in well-cleaned sterilized cages. This research was allowed by the ethics committee of Shahid Bahonar University and Kerman Neuroscience Research Center (Kerman, Iran). In our model, two different doses of lead (40 and $80 \mathrm{mg} \mathrm{kg}^{-1}$ body weight) were used for 45 days followed by early administration of chelating agents. Experiments were done on 7-week-old Wistar male rats. In this study, we used two doses of 40 and $80 \mathrm{mg} \mathrm{kg}^{-1}$ body weight. Chelation therapy was done after lead administration. Animals were classified as follows (Table 1): the first group (Control group) was given normal food and distilled water to drink. Rats in this group were killed at the end of lead administration (day 45). 
<smiles>O=C(O)c1ccc(-n2nc(-c3ccccc3O)nc2-c2ccccc2O)cc1</smiles>

(A)

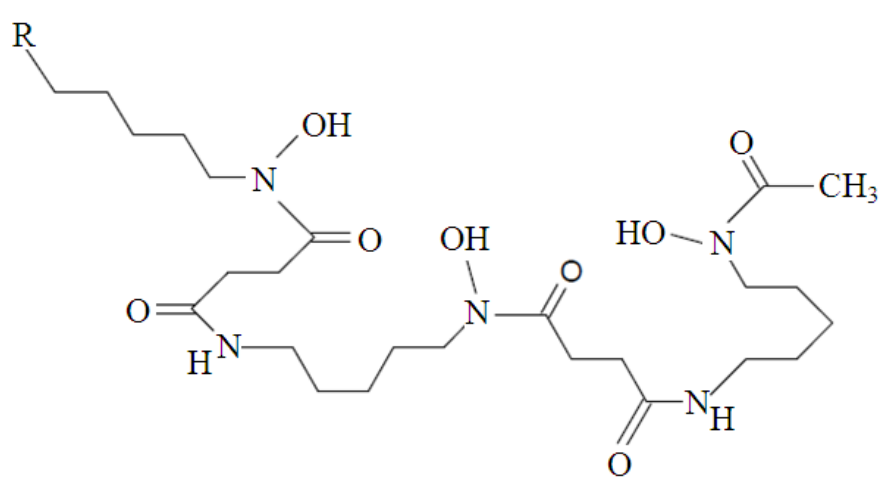

(B)

Fig. 1. Chemical structure of Deferasirox (A) and Desferrioxamine (B)

Table 1. Classification of animals

\begin{tabular}{lll}
\hline & Control group & \\
\hline All rats & $\begin{array}{l}\text { Low and/or high } \\
\text { doses drinking group }\end{array}$ & $\begin{array}{l}\text { Before chelation therapy } \\
\text { Without chelation therapy (vehicle) } \\
\end{array}$ \\
& $\begin{array}{l}\text { Single therapy with DFX (140 } \mathrm{mg} \mathrm{kg}^{-1} \text { body weight) } \\
\text { Single therapy with DFO (150 } \mathrm{mg} \mathrm{kg}^{-1} \text { body weight) } \\
\text { Combined therapy with DFX (70 } \mathrm{mg} \mathrm{kg}^{-1} \text { body) } \\
+ \text { DFO (75 } \mathrm{mg} \mathrm{kg}^{-1} \text { body weight) }\end{array}$ \\
\hline
\end{tabular}

The concentrations of lead and iron in tissues in control group were compared with the groups that received lead and chelators. This was done to find out the normal amount of lead and iron in the body of the rats during the research period and to ensure that there were no unknown roots of exposure to lead and iron during the full course of research.

The second group (low dose drinking of lead) was given water containing $40 \mathrm{mg} \mathrm{Pb}^{2+} / \mathrm{kg}$ body weight and the third group (high dose drinking of lead) was

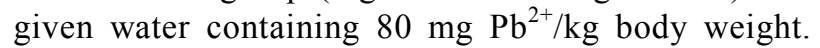
The given dose volume for rats was calculated based upon their weight. Oral administration was made daily. The control group involved 5 animals and each of other groups had 25 animals. After 45 days, intoxication symptoms appeared and high and low doses groups were divided to 5 sub-groups: 1 . Before chelation therapy 2. Without chelation therapy 3 . Single therapy with DFX 4. Single therapy with DFO and 5. Combined therapy with DFO+DFX. In order to compare the lead and iron concentrations in tissues, before and after chelation therapy, one group was selected as before chelation therapy group (vehicle). The rats, in this group, were anesthetized with ether vapors and were killed. Kidney, heart, liver and spleen samples were weighed, dried and collected for determination of lead and iron content. In order to investigate the effect of passing time in removing lead from rat organs, without chelation therapy group was selected. In order to investigate the capability of two chelators (DFX and DFO) to remove lead from the body, chelation therapy was done. chelators were given immediately after lead administration for 10 days. Chelators DFX and DFO were given orally and intraperitoneally as single and combined therapies. Doses of DFX and DFO were 140 and $150 \mathrm{mg} / \mathrm{kg}$ body weight, respectively. Lead toxicity signs appeared in rats, were removed in short term after drug application. At the end of chelation therapy, animals were killed and tissues were taken, dried and collected for determination of $\mathrm{Pb}$ and $\mathrm{Fe}$ concentrations. The samples were put in an oven at 60 for 3 days. Then, samples were digested by $1 \mathrm{~mL}$ of $\mathrm{HNO}_{3}$ per $1 \mathrm{~g}$ of sample weight. After digestion, the 
solutions were vaporized with the addition of $0.5 \mathrm{~mL}$ of $\mathrm{H}_{2} \mathrm{O}_{2}$ under the hood. Afterwards, the residues was diluted with distilled water to $10 \mathrm{~mL}$ volume.

\subsection{Apparatus}

Measurement of lead and iron in various tissues were performed by a Varian Flame Atomic Absorption Spectrometer (FAAS). A microwave oven, model CEM MDS 200, was used to elimination the water content present in organs and to facilitate digestion. Also a Mettler analytical balance Model AE 160 was used in this research.

\subsection{Statistical Analysis}

Determination of lead and iron in samples were performed by atomic absorption spectrometry by the standard addition method. The values are explained as mean values (minimum five separate determinations) Standard Error of the Mean (SEM). The data were subjected to statistical analysis by Student's t-test; $\mathrm{p}<0.05$ was considered significant.

\section{RESULTS AND DISCUSSION}

\subsection{Effect of lead on Body Weight and Food Intake Changes in Wistar Rats}

There wasn't remarkable difference between the groups in the initial body weight of the rats (mean 230 $\mathrm{g})$, but at the end of lead application test, those given lead in their diet had remarkable weight loss (Table 2). Evaluation of the weights in this study indicates that dietary treatment affected the food intake, whereby rats given normal diet consumed more food than those given lead.

\subsection{Symptoms of Lead Toxicity in Wistar Rats}

A significant difference between control and treatment groups was observed. The lead accumulation in tissues at the $80 \mathrm{mg} \mathrm{kg}^{-1}$ dose was greater than the group at $40 \mathrm{mg} \mathrm{kg}^{-1}$. The following, lead toxicity signs in animals were observed: appearance of red dots around eyes, flaccid, weakness, hypotonic muscles, irritability, decline weight and loss of hair. Also, our results shown, as lead concentration increased in tissues, iron concentration decreased. The maximum amount of lead accumulation was found in kidney followed by liver and spleen.

\subsection{Effect of Chelators on Lead Level in Various Tissues after Treatment in Wistar Rats}

The effects of chelators (DFX and DFO) application on lead concentration in the various tissues are shown in Table 3 and 4. After chelation therapy with chelators, as single and combined, our results shown that $\mathrm{Pb}$ concentration was significantly decreased and also toxicity symptoms reduced. There is statistical difference between DFX and DFO in removing of lead in different tissues. The t-test was applied to the results assuming the certified values were the true values. When to compare single therapy efficiencies of chelators in this study, DFX was more effective in decreasing lead concentration in all tissues special from liver. Our results show treatment by combining chelators $(\mathrm{DFX}+\mathrm{DFO})$ is more effective to reduce the lead concentration than mono therapy in all tissues.

\subsection{Effect of Chelators on Iron Level in Various Tissues after Treatment in Wistar Rats}

The difference between iron concentrations before and after chelation therapy is remarkable. Iron concentration was lowest in the group that had the highest lead concentration, which is probably because of remarkable interference that could take place by lead through iron uptake mechanism. Interactions between lead and iron have not been previously reported. It is not clear whether lead interferes with iron absorption and/or the subsequent metabolism, but it may be possible that lead absorption takes place along with pathways for essential metals. In addition to, iron level after chelation therapy significantly reduced thus consumption of iron tablet is recommended to return iron level to its normal state. The results of iron concentrations before and after chelation therapies are shown in Table 5 and 6. Combination of DFX+DFO shows more efficiency in decreasing iron level.

\subsection{Effect of Biological System in Removing Lead from Various Tissues in Wistar Rats}

In order to investigate the spontaneous elimination of lead from body by the biological system, one group was treated without chelation therapy (Saljooghi and Fatemi, 2010; 2011). Removal of lead by the biological system in this group is not noticeable. 
Faezeh Dahooee Balooch et al. / American Journal of Pharmacology and Toxicology 8 (4): 134-140, 2013

Table 2. Body weight over 45 days for rats in different group (Values are mean for the number of observation in parentheses)

\begin{tabular}{llll}
\hline Group & Control & Low dose drinking & High dose drinking \\
\hline Initial body weight* $(\mathrm{g})$ & $227 \pm 6(5)(1$ day) & $225 \pm 4(5)(1$ day) & $230 \pm 6(5)(1$ day) \\
Final body weight* $(\mathrm{g})$ & $285 \pm 5(5)(45$ day $)$ & $260 \pm 7(5)(47$ day $)$ & $257 \pm 4(5)(47$ day) \\
\hline
\end{tabular}

*Mean of five determination \pm standard deviation

Table 3. Concentration of lead $(\mathrm{mg} / \mathrm{kg})$ in control and low dose groups

\begin{tabular}{lllllll}
\hline Group & Control & $\begin{array}{l}\text { Before } \\
\text { chelation } \\
\text { therapy }\end{array}$ & $\begin{array}{l}\text { Without } \\
\text { chelation } \\
\text { therapy }\end{array}$ & $\begin{array}{l}\text { Chelation } \\
\text { therapy } \\
\text { with DFX }\end{array}$ & $\begin{array}{l}\text { Chelation } \\
\text { therapy } \\
\text { with DFO }\end{array}$ & $\begin{array}{l}\text { Chelation } \\
\text { therapy with } \\
\text { DFX+DFO }\end{array}$ \\
\hline Heart & $0.048 \pm 0.008$ & $0.510 \pm 0.023$ & $0.509 \pm 0.019$ & $0.175 \pm 0.012$ & $0.251 \pm 0.014$ & $0.115 \pm 0.015$ \\
Kidney & $0.032 \pm 0.005$ & $0.913 \pm 0.023$ & $0.913 \pm 0.016$ & $0.469 \pm 0.023$ & $0.431 \pm 0.016$ & $0.183 \pm 0.014$ \\
Liver & $0.037 \pm 0.006$ & $0.632 \pm 0.018$ & $0.631 \pm 0.024$ & $0.213 \pm 0.017$ & $0.365 \pm 0.015$ & $0.153 \pm 0.016$ \\
Spleen & $0.052 \pm 0.023$ & $0.502 \pm 0.012$ & $0.501 \pm 0.025$ & $0.308 \pm 0.018$ & $0.387 \pm 0.012$ & $0.189 \pm 0.014$ \\
\hline
\end{tabular}

The number of rats in each group was five; Results are represented as arithmetic means \pm SEM, Significant at $\rho<0.05$ when compared with control.

Table 4. Concentration of lead $(\mathrm{mg} / \mathrm{kg})$ in control and high dose groups

\begin{tabular}{lllllll}
\hline Group & Control & $\begin{array}{l}\text { Before } \\
\text { chelation } \\
\text { therapy }\end{array}$ & $\begin{array}{l}\text { Without } \\
\text { chelation } \\
\text { therapy }\end{array}$ & $\begin{array}{l}\text { Chelation } \\
\text { therapy } \\
\text { with DFX }\end{array}$ & $\begin{array}{l}\text { Chelation } \\
\text { therapy } \\
\text { with DFO }\end{array}$ & $\begin{array}{l}\text { Chelation } \\
\text { therapy with } \\
\text { DFX+DFO }\end{array}$ \\
\hline Heart & $0.048 \pm 0.008$ & $0.631 \pm 0.017$ & $0.629 \pm 0.021$ & $0.389 \pm 0.019$ & $0.421 \pm 0.023$ & $0.111 \pm 0.012$ \\
Kidney & $0.032 \pm 0.005$ & $1.182 \pm 0.024$ & $1.181 \pm 0.018$ & $0.674 \pm 0.025$ & $0.701 \pm 0.019$ & $0.137 \pm 0.021$ \\
Liver & $0.037 \pm 0.006$ & $0.853 \pm 0.013$ & $0.850 \pm 0.021$ & $0.281 \pm 0.023$ & $0.432 \pm 0.018$ & $0.128 \pm 0.027$ \\
Spleen & $0.052 \pm 0.023$ & $0.787 \pm 0.021$ & $0.786 \pm 0.018$ & $0.456 \pm 0.019$ & $0.561 \pm 0.011$ & $0.192 \pm 0.016$ \\
\hline
\end{tabular}

The number of rats in each group was five; Results are represented as arithmetic means \pm SEM, Significant at $\rho<0.05$ when compared with control.

Table 5. Concentration of iron $(\mathrm{mg} / \mathrm{kg})$ in control and low dose groups

\begin{tabular}{|c|c|c|c|c|c|c|}
\hline Group & Control & $\begin{array}{l}\text { Before } \\
\text { chelation } \\
\text { therapy }\end{array}$ & $\begin{array}{l}\text { Without } \\
\text { chelation } \\
\text { therapy }\end{array}$ & $\begin{array}{l}\text { Chelation } \\
\text { therapy } \\
\text { with DFX }\end{array}$ & $\begin{array}{l}\text { Chelation } \\
\text { therapy } \\
\text { with DFO }\end{array}$ & $\begin{array}{l}\text { Chelation } \\
\text { therapy with } \\
\text { DFX+DFO }\end{array}$ \\
\hline Heart & $6.52 \pm 0.33$ & $6.32 \pm 0.26$ & $6.30 \pm 0.18$ & $5.43 \pm 0.32$ & $5.67 \pm 0.23$ & $5.14 \pm 0.28$ \\
\hline Kidney & $4.85 \pm 0.28$ & $3.61 \pm 0.31$ & $3.62 \pm 0.26$ & $3.05 \pm 0.23$ & $3.19 \pm 0.31$ & $2.67 \pm 0.34$ \\
\hline Liver & $6.53 \pm 0.33$ & $5.61 \pm 0.29$ & $5.62 \pm 0.21$ & $4.88 \pm 0.24$ & $5.16 \pm 0.27$ & $4.23 \pm 0.27$ \\
\hline Spleen & $4.36 \pm 0.31$ & $4.02 \pm 0.28$ & $4.00 \pm 0.24$ & $3.37 \pm 0.29$ & $3.67 \pm 0.31$ & $3.01 \pm 0.35$ \\
\hline
\end{tabular}

The number of rats in each group was five; Results are represented as arithmetic means \pm SEM, Significant at $\rho<0.05$ when compared with control.

Table 6. Concentration of iron $(\mathrm{mg} / \mathrm{kg})$ in control and high dose groups

\begin{tabular}{|c|c|c|c|c|c|c|}
\hline Group & Control & $\begin{array}{l}\text { Before } \\
\text { chelation } \\
\text { therapy }\end{array}$ & $\begin{array}{l}\text { Without } \\
\text { chelation } \\
\text { therapy }\end{array}$ & $\begin{array}{l}\text { Chelation } \\
\text { therapy } \\
\text { with DFX }\end{array}$ & $\begin{array}{l}\text { Chelation } \\
\text { therapy } \\
\text { with DFO }\end{array}$ & $\begin{array}{l}\text { Chelation } \\
\text { therapy with } \\
\text { DFX+DFO }\end{array}$ \\
\hline Heart & $6.52 \pm 0.33$ & $6.06 \pm 0.23$ & $6.04 \pm 0.27$ & $5.43 \pm 0.29$ & $5.77 \pm 0.27$ & $4.87 \pm 0.33$ \\
\hline Kidney & $4.78 \pm 0.28$ & $3.75 \pm 0.26$ & $3.79 \pm 0.31$ & $3.31 \pm 0.35$ & $3.51 \pm 0.29$ & $3.04 \pm 0.25$ \\
\hline Liver & $6.21 \pm 0.33$ & $5.73 \pm 0.25$ & $5.77 \pm 0.28$ & $5.41 \pm 0.31$ & $5.34 \pm 0.24$ & $5.03 \pm 0.35$ \\
\hline Spleen & $4.36 \pm 0.31$ & $4.01 \pm 0.28$ & $3.98 \pm 0.23$ & $3.65 \pm 0.29$ & $3.87 \pm 0.34$ & $3.16 \pm 0.31$ \\
\hline
\end{tabular}

The number of rats in each group was five; Results are represented as arithmetic means \pm SEM, Significant at $\rho<0.05$ when compared with control.

\section{CONCLUSION}

One of the most effective ways to eliminate toxic metals from the biological system is chelation therapy.
Recently, many compounds have been studied as chelating agents in animal models. Clinical evaluations of some chelators in removing of toxic metals in rats have been previously reported by (Fatemi et al., 2009; 
2011; 2012). Lead is disharmonic element with contexture of body. Against other vital elements such as zinc and selenium, tissues of body identify lead as poison. Most of lead doses accumulate in kidney and liver. Generally, iron chelators are small molecules (molecular mass $\sim 100-900$ Da) containing oxygen, nitrogen or sulfur donor atoms that form coordinate bonds with bound iron. Iron chelators exhibit variable propensities to bind other metals, including copper, zinc, magnesium, calcium and others. In order to investigate the abilities of DFX and DFO chelators in removing lead from the body, some studies were carried out on rats as biological model. DFO is the common drug for the treatment of iron overload in patients. Naturally occurring siderophores provide excellent models for the development of therapeutic useful iron chelators. Although DFO is a large and a highly hydrophilic molecule, it gains entry into the liver via a facilitated transport system. Therefore, it can interact with both hepatocellular and extracellular iron promoting urinary and biliary iron excretion (Ma et al., 2012) DFX is a new drug that indicates benefit properties. It can penetrate membranes easily and possesses good oral availability. Recently, many studies have reported the high absorption/distribution, long-term efficacy and safety of DFX and DFO in removing some toxic metals and treating iron overload in patients with $\beta$-thalassemia major (Cappellini, 2008; Tubafard and Fatemi, 2008; Lal et al., 2013). A short-term experimental model was applied in order to accelerate the preliminary testing procedure. The effects of chelators on lead and iron level were notable. In order to investigate the capabilities of known chelators, we have done the distribution of lead and studied amount of accumulation and toxic effects of lead in different tissues. After application of chelators, the lead level decreased to control group level, which shows that DFX and DFO effectively increases the removal of lead in rats and also toxicity symptoms were greatly decreased. Results of before and after chelation therapy show that combined (DFX+DFO) therapy enhances the removal of lead considerably and treat the side effects and general toxicity symptoms caused by lead. Also, the toxicity and side effects of combined therapy are lower than single therapy. In order for a chelating agent to exert its pharmacological effect, a drug must be able to reach the target sites at sufficient concentration. Each of chelators has a different target tissue; therefore, combination of them can help to removing lead from various tissues effectively. DFX, by virtue of its small size and ability to penetrate cells (Ma et al., 2012), has capability of efficiency scavenging excess toxic metal and DFO, because of high affinity hexadentate ligand to complex with metals, could be chelate intracellular metals. By considering of these properties, combined therapy is more effective than single therapy. The combined therapy procedure is likely to increase metal excretion, target specific metal tissues, minimize side effects (by virtue of the use of lower doses) and improve compliance. From pervious results that reported by Fatemi. Amiri et al. (2007); Tubafard and Fatemi (2008) and Fatemi et al. (2011; 2012) and our present results, it can be concluded that two chelators (DFX+ DFO) are more effective as combined therapy than single therapy in removal of lead from the body. Therefore, DFX +DFO combination seems to be a promising drug of lead-mobilizing agent. This study might be effective for preliminary testing of the ability of chelating agent in removing lead. Therefore after essential preclinical experiments, this could be suggested for human administration.

\section{ACKNOWLEDGEMENT}

The researchers are thankful to the head and director of Kerman Neuroscience Research Center and Shahid Bahonar University of Kerman Faculty Research Funds for their support of these investigations.

\section{REFERENCES}

Amiri, A., S.J. Fatemi and S.N. Fatemi, 2007. Removal of thallium by combining desferrioxamine and deferiprone chelators in rats. Biometals, 20: 159163. PMID: 16927173

Cappellini, M.D., 2008. Long-term efficacy and safety of deferasirox. Blood Rev., 22: 35-41. PMID: 19059055

Fatemi, S.J., A.S. Saljooghi, F.D. Balooch, M. Iranmanesh and M.R. Golbafn, 2011. Chelation of cadmium by combining deferasirox and deferiprone in rats. Toxicol. Indus. Health, 27: 371-377. DOI: 10.1177/0748233710388451

Fatemi, S.J., A.S. Saljooghi, F.D. Balooch, M. Iranmanesh and M.R. Golbafan, 2012. Removal of cadmium by combining deferasirox and desferrioxamine chelators in rats. Toxicol. Indus. Health, 28: 35-41. DOI: $10.1177 / 0748233711403192$ 
Fatemi, S.J., S. Tubafard and B. Nadi, 2009. Evaluation of the effect of cadmium on rat organs and investigation of diethyl carbamate as an oral drug in treatment of cadmium toxicity. Med. Chem. Res., 18: 179-186. DOI: 10.1007/S00044-008-9118-Z

Foyer, C.H. and G. Noctor, 2002. Oxygen processing in photosynthesis: Regulation and signalling. New Phytol., 146: 359-388. DOI: 10.1046/j.14698137.2000.00667.x

Heinz, U., K. Hegetschweiler, P. Acklin, B. Faller and R. Lattmann et al., 1999. 4-[3,5-Bis(2-hydroxyphenyl)1,2,4-triazol-1-yl]- benzoic Acid: A Novel Efficient and Selective Iron(III) Complexing Agent. Angewandte Chem. Int. Edn., 38: 2568-2570. DOI: 10.1002/(SICI)1521-

3773(19990903)38:17<2568::AID-

ANIE2568>3.0.CO;2-C

Ibrahim, N.M., E.A. Eweis, H.S. El-Beltagi and Y.E. Abdel-Mobdy, 2012. Effect of lead acetate toxicity on experimental male albino rat. Asian Pac. J. Trop. Biomed., 2: 41-46. DOI: 10.1016/S22211691(11)60187-1

Iranmanesh, M., S.J.A. Fatemi, R. Ebrahimpour and F.D. Balooch, 2013. Chelation of chromium(VI) by combining deferasirox and deferiprone in rats. Biometals, 26: 465-471. DOI: 10.1007/S10534-0139631-5

Lal, A., J. Porter, N. Sweeters, V. Ng and P. Evans et al., 2013. Combined chelation therapy with deferasirox and deferoxamine in thalassemia. Blood Cells Mol. Dis., 50: 99-104. PMID: 23151373

List, A.F., M.R. Baer, D.P. Steensma, A. Raza and J. Esposito et al., 2009. Two-Year Analysis of Efficacy and Safety of Deferasirox (Exjade ${ }^{\circledR}$ ) Treatment in Myelodysplastic Syndrome Patients Enrolled in the US03 Study. Blood, 114: 3829-3829.
Ma, Y., T. Zhou, X. Kong and R.C. Hider, 2012. Chelating agents for the treatment of systemic iron overload. Curr. Med. Chem., 19: 2816-2827. DOI: 10.2174/092986712800609724

Navarro-Moreno, L.G., M.A. Quintanar-Escorza, S. Gonzalez, R. Mondragon and J. Cerbon-Solorzano et al., 2009. Effects of lead intoxication on intercellular junctions and biochemical alterations of the renal proximal tubule cells. Toxicol. Vitro, 23: 1298-1304. DOI: 10.1016/j.tiv.2009.07.020

Saljooghi, A.S. and S.J. Fatemi, 2011. Removal of thallium by deferasirox in rats as biological model. J. Applied Toxicol., 31: 139-143. DOI: 10.1002/jat. 1573

Saljooghi, A.S. and S.J.A. Fatemi, 2010. Clinical evaluation of Deferasirox for removal of cadmium ions in rat. BioMetals, 23: 707-712. DOI: 10.1007/s10534-010-9337-X

Sansar, W., S. Ahboucha and H. Gamrani, 2011. Chronic lead intoxication affects glial and neural systems and induces hypoactivity in adult rat. Acta Histochemica, 113: 601-607. DOI: 10.1016/j.acthis.2010.06.005

Tubafard, S. and S.J. Fatemi, 2008. Chelation of bismuth by combining desferrioxamine and deferiprone in rats. Toxicol. Ind. Health, 24: 235-240. DOI: 10.1177/0748233708095771

Tubafard, S., S.J. Fatemi, A.S. Saljooghi and M. Torkzadeh, 2010. Removal of vanadium by combining desferrioxamine and deferiprone chelators in rats. Med. Chem. Res., 19: 854-863. DOI: $10.1007 / \mathrm{s} 00044-009-9235-3$ 